\title{
Design and Implementation of Overcurrent Relay to Protect the Transmission Line
}

\author{
Mohammed A. Ibrahim ${ }^{1}$, Waseem Kh. Ibrahim ${ }^{2}$, Ali N. Hamoodi ${ }^{3}$ \\ ${ }^{1,2,3}$ Northern Technical University, Technical Engineering College, Mosul, Iraq.
}

\begin{abstract}
Power system is prone to faults, because of disoperation of the system or by the natural disasters. This may be caused with damage the components of power system leading to great tasked for their subrogation and cutting the power supply to customers. In this period, much power is exhausted and this stipulation is increasingly transmitted by using transmission line, from one side or place to another side. Different kinds fault may occur in these transmission lines. The major purpose of this article is to analysis and studies the different faults and also declares the impact on transmission line. This work is approach to MATLAB/SIMULINK package. In this work we connect a $100 \mathrm{Km}$ terco type and the various cases of fault types are studied where over current relays (OCRs) are used in this work.
\end{abstract}

Keywords: Circuit breaker, Current transformers, Medium transmission line, Power system, Voltage transformers

\section{INTRODUCTION}

Power system is not defendable to faults, because of disoperation of the system or by the natural disaster. This may be caused with damage the components of power system leading to great tasked for their subrogation and cutting the power supply to customers, these steps are required to sustain faults in a power system. Protection system must be minimized the damage in main components, this is realized by using the methodologies and techniques of power system protection [1-3]. Controller units based relays are used for monitoring the power system performance depending on (VTs) and (CTs) respectively. For confirm a safe and credible of protection relays before putting the substation, therefore these relays must be tested. In the ring and radial sub transmission system, and distribution system. OCRs are broadly used. During the same fault, relays will detect the greatly different currents at different locations of these relays $[4,5]$. For each contingent fault location, relays must be regulated the sequence of operation according to the coordination methods, so that the faulted stanza to furnish adequate montage ambits unrested immoderate time delay [68]. In ring fed distribution networks, the OCRs are a largely hindered optimization issue. The eventual target being a meliorated power system credibility. The determination of the pickup current (Ipu) setting and time dial setting (TDs) of the relay is core of coordination [9].

Fault analysis can assist to choice and develop a best device for protection. C.B. and it ratings depend on triple line fault must checked because of the big value of triple line fault current as compared with the other fault current. The aim of this work is to study the (balance \& unbalance) fault in the power system. By using Matlab simulation kinds [10-12].

\subsection{Literature Review}

Maiji and Ghosh [2], studied the simplest kind of fault including maximum current, but fortunately it takes place infrequently. For this cause, balanced short-circuit computation is achieved to find these high currents. The article has displayed the modeling and simulation of over current relay on MATLAB/SIMULINK. The suggested model offers poignant means for articulating the actions of over current relay. It is declaring that these model offer effective mans for articulating the post of over current relay under different operating scenarios. Additionally, the systematic unfolding diction of model development and deportment analysis name lies that this article could also ministering as guide to develop homologue relay models and benchmark performance. The relay has good fortuitous in term of it sensitivity.

Akhikpemelo, Evbogbai and Okundamiya [3], studied the effect of the relays in the transmission line in order to be coordinated exactly to save primary supply like the backup protection to avoid multifunction. Relay operating time is calculated by using MATLAB GUI model. They concluded that the exact coordination of the various OCRs characteristics can be obtained from simulation results.

The purpose of this paper is to modulate, and simulation the transmission line with OCRs based on Matlab/Simulink. Depending on the results that obtained by Matlab/Simulink is selected due to its lability to model power system components.

\section{FAULTS AND CLASSIFICATIONS}

When the power system works neath balanced clauses with respective components carrying. Ordinary the bus potential and the load current including the described limits. A fault in the circuit can be obtained due to the failure that cognizable with the ordinary current flow. When the system insulation fails due to low impedance itinerary either between phase (s) to ground or phases a short [13-17]. Circuit fault will occur; this short circuit faults are classified as [18]:

- Symmetrical faults.

- Unsymmetrical faults. 


\subsection{Symmetrical Faults}

In these kinds, all the phases are short circuit to earth or to each other. These faults are considered as a balance case and giving a sense that the system remain symmetrical $[19,20]$. The bulks severe kind of fault is that included maximum current, for this reason, the calculations of balanced short circuit case are achieved to find these maximum currents.

\subsection{Unsymmetrical Faults}

Unsymmetrical fault included solely one phase or two phases. In this type of faults, this line gets unbalanced. Such kinds of faults happen between lines or line to ground. An unsymmetrical series fault is occurred between phase to ground or phases, while unsymmetrical shunt fault considered as an unbalanced in the line impedances [21-23]. Three phases shunt fault can be divided as:

- Single line to ground fault (L-G).

- Double lines faults (L-L).

- Double line to ground fault (L-L-G).

- Triple line fault (L-L-L).

- Triple line to ground fault (L-L-L-G).

\section{OVER CURRENT RELAYS (OCRs)}

An OCR furnishes against current; the function of this is to compare the actual measured value with preset value. The logical representation of this OCR is given in figure (1). When the value of the input current overcomes the littleness value, the relay will sense this increasing in the current value and sending a trip signal to the C.B. and open its contact to disjunction the protected device. Once the relay locates a fault, the clause for this case is called fault pickup. After picking up the fault, relay can transmit a trip signal instantaneously. (instantaneously over current relay) or it can be bidding for a certain time prior releasing a trip signal (time over current case) [24, 25].

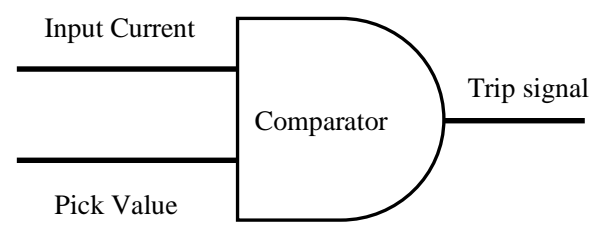

Figure 1: Logical exemplification of Over-Current Relay

OCRs can be classified according to their operation in to three categories $[2,3]$ :

1- Instantaneous OCRs: These relays transmit instantaneously as trip reinstating to the C.B. as detecting the fault without having an intentional time delay.

2- Definite Time OCRs: These types of relay are charity for backup protection. If the distance relay does not send a trip to the C.B. after fault occurring, then remoteness a certain time delay, the OCR will transmit a trip to the C.B.

3- Inverse Definite Minimum Time (IDMT) OCRs: These relays have an inverse time property. The operating time of theses relays has an inverse proportional with the fault current, when this value become higher, the operating time will become lower, it enables to be sorted for a wide span of fault currents and operating time. OCRs determine the operating time depending on their characteristics and associated parameters.

\section{OVER CURRENT RELAY ALGORITHM}

Figure (2) represents the algorithm of overcurrent protection for transmission line, an operational operator is used for compared between the setting current (reference current) and the fault current. A comparison is made according to the fault current value, when this value overcome the setting value a trip signal is sending to the (C.B.) and protecting the transmission line.

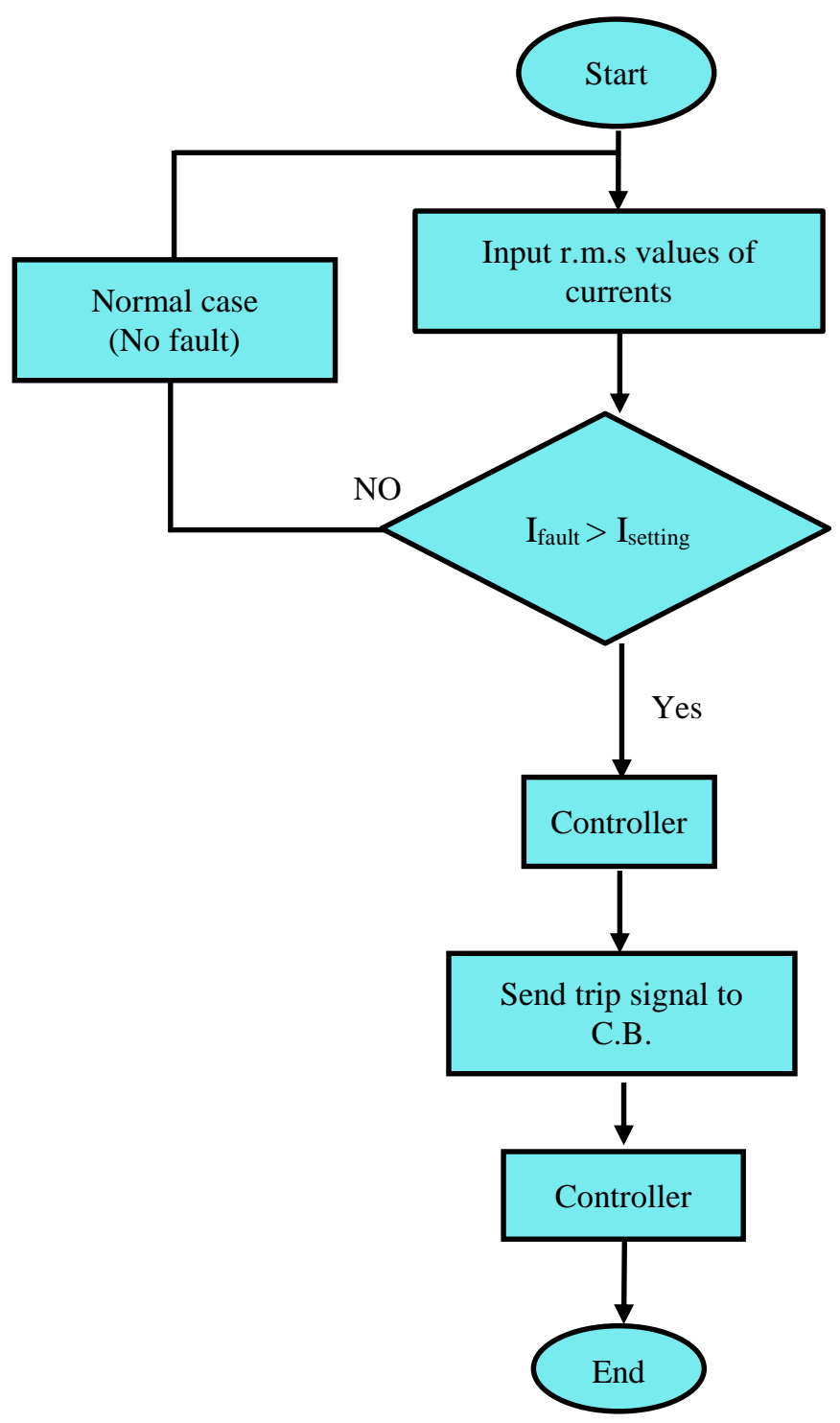

Figure 2: Flow chart of overcurrent protection 


\section{MODELING AND SIMULATION}

Table.1 depicts the power system parameters and relay preparations. The ratio of $\mathrm{CT}$ is relying on the calculate premium of the full load current. The length of the line has a length with $100 \mathrm{~km}$ power system parameters for phase and earth faults are variables, earth fault is naturally set lower than the current premium at full load, while for phase fault is setting above than the current premium at full load in order to locate the high impedance fault at ground fault.

Table1: Network and relay setting parameters

\begin{tabular}{ll}
\hline Parameters & Values \\
\hline Source Short Circuit Level (MVA) & 110 \\
Source VLL $(\mathrm{KV})$ & 230 \\
Line Length $(\mathrm{Km})$ & 100 \\
Sequence Resistance, R $(\Omega)$ & 2.20 \\
Sequence Inductance, L $(\mathrm{mH})$ & 25 \\
Sequence Capacitance, C $(\mu \mathrm{F})$ & 2.5 \\
Line VLL $(\mathrm{V})$ & 400 \\
Network Frequency $(\mathrm{Hz})$ & 50 \\
\hline
\end{tabular}

\subsection{Description of model}

The Multifunctional relay model is tested under various condition of the fault. terco (named MV2221) transmission line that adopted in this work is shown in figure (3). The transmission lines consist of $230 \mathrm{KV}, 50 \mathrm{~Hz}$ and $100 \mathrm{Km}$ length. Figure (3) illustrates the model of relay and network that is initialized using MATLAB/Simulink package. The chosen network represents artless spur transmission line girded to an equivalent circuit with 3-phase power source at the first side and the other side is girded to the load. The currents phases lines in the simulation model are blue, yellow and red. When ground fault is happened a residual current will pass to the earth, this case will not occur at phase to phase fault. Figure (3) illustrates the terco model of $(230 \mathrm{KV})$ and $(100 \mathrm{Km})$ that adopted in this work.

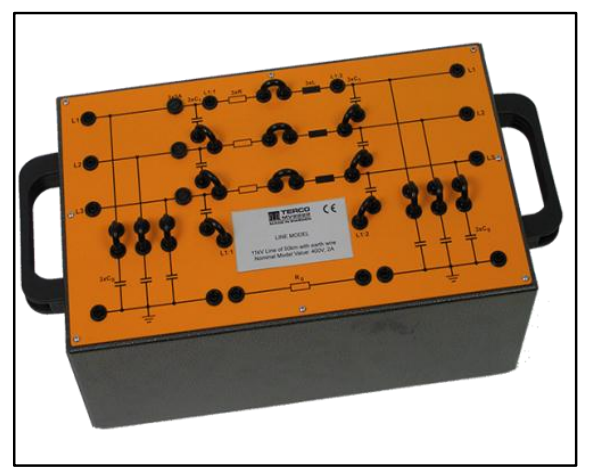

Figure 3: MV2221 Line Model

\section{EXPERIMENTAL AND SIMULATION RESULTS}

In extra high voltage lines, the station (generation station) and load centres are connected. When, the generation legs are distant from the load center running over few hundreds of kilometers. The protection of transmission line is very grave issue in electrical power system because $(83 \%-86 \%)$ of faults in the overhead lines are occurring. Figure (4) represents the circuit diagram of OCRs protection represented by Matlab/Simulink.

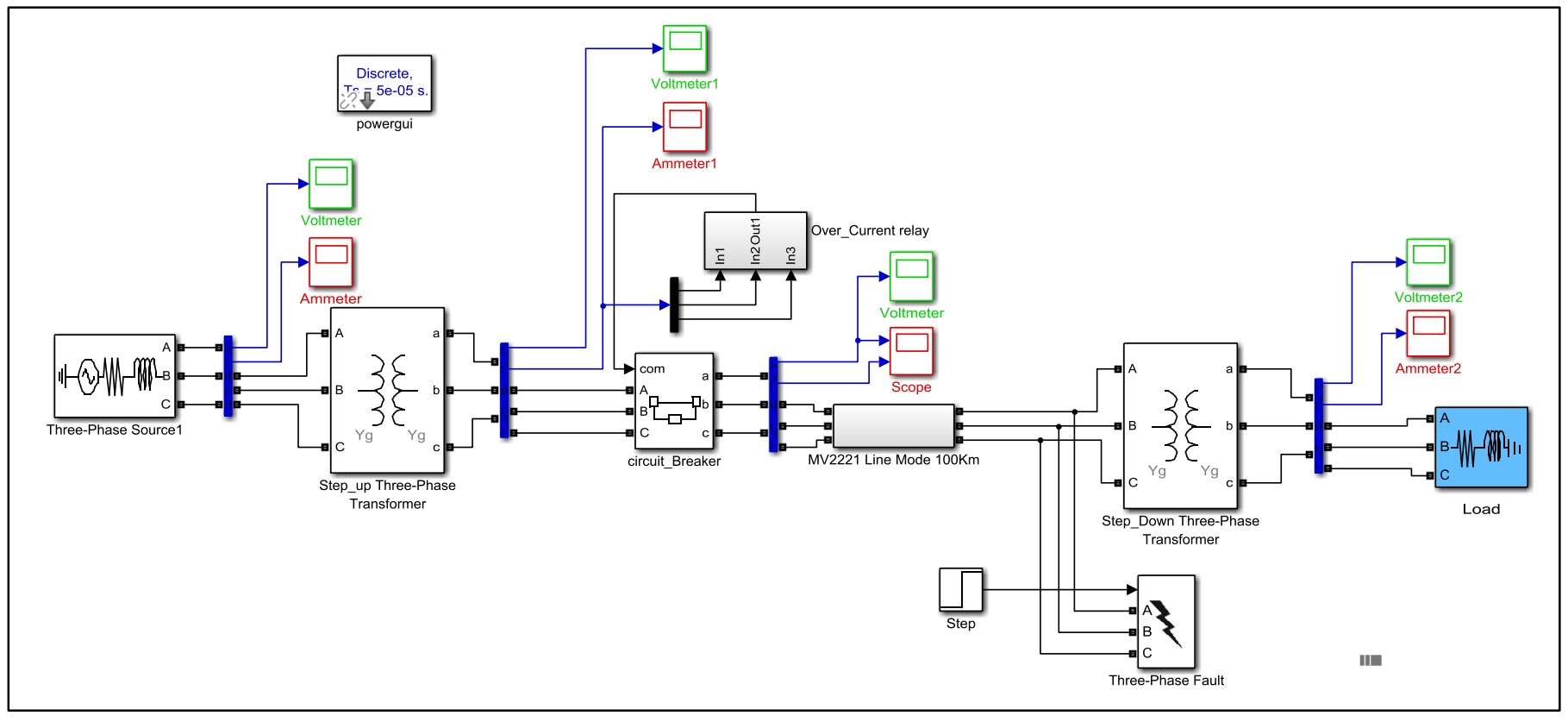

Figure 4: Matlab Simulink model of used model 


\subsection{Normal Case (Without Fault):}

In medium transmission line, if there is no fault, the output signal will be normal with balance value of current as given in figure (5). These energies are considered the reference initial parameters. When a small change is occurred is these parameters, and then the phase that with this case is considered as fault clauses.

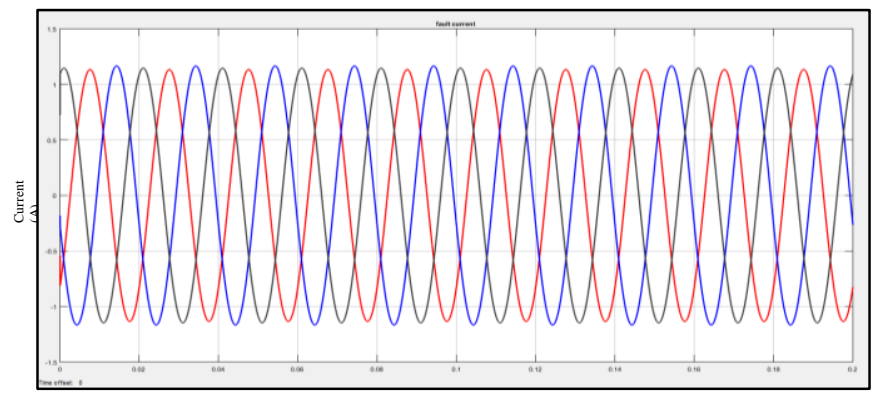

Figure 5: Current signal without fault related

\subsection{L-G Fault}

Figure (6) represents the line to ground (A-G, B-G, C-G) fault. The signal of (A) phase have more transient or peak value of (A-G) fault system. The coefficients of energy related with respective phase and ground are formulated, these coefficients are changed in (A-G) fault system. The simulation of line to ground fault happens when one phase is shorted to ground and the fault is detecting at the fault location. The output waveforms are depicted in figure (7).

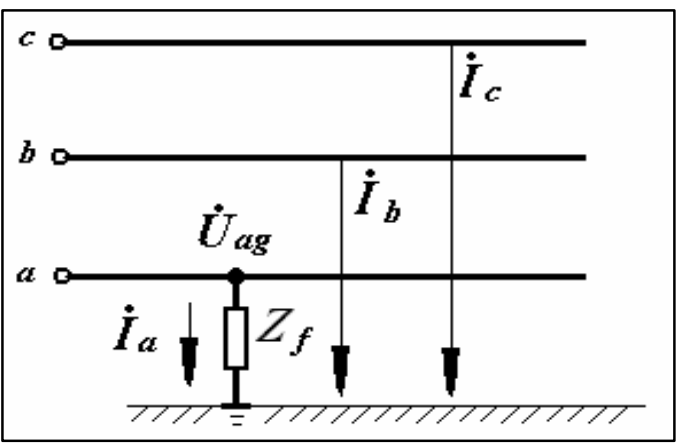

Figure 6: Single line to ground fault

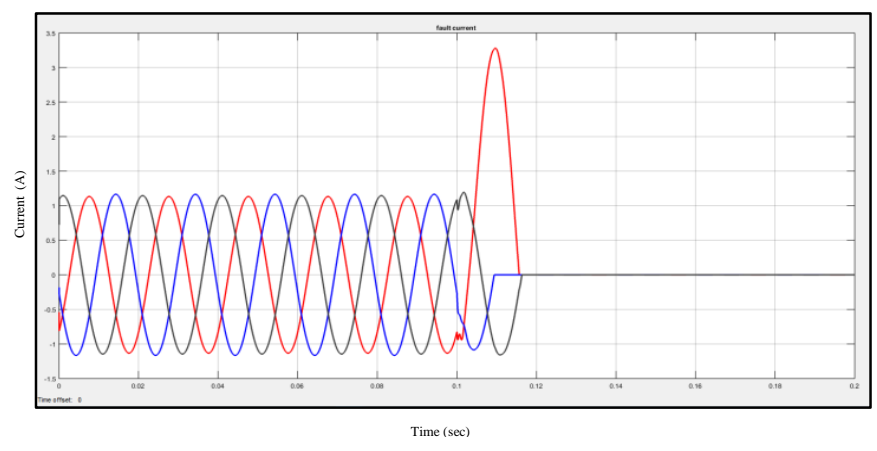

Figure 7: Current signal of single line-to-ground fault (A-G)

\subsection{L-L-G Fault}

For A-G fault. The transients fault for A, B and zero signals are bigger than the other phases. The seamed energy in respective phase to ground is depended and all coefficients are calculated. The energy seamed with all analyses and coefficients of A, B phases and ground is altered and called $\mathrm{AB}-\mathrm{G}$ fault system as shown in figure (8). Figure (9) represents the current waveforms of double line to ground fault.

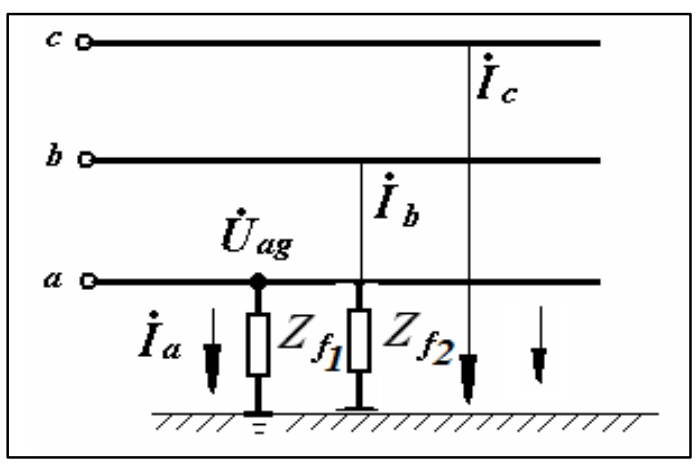

Figure 8: Double line to ground fault

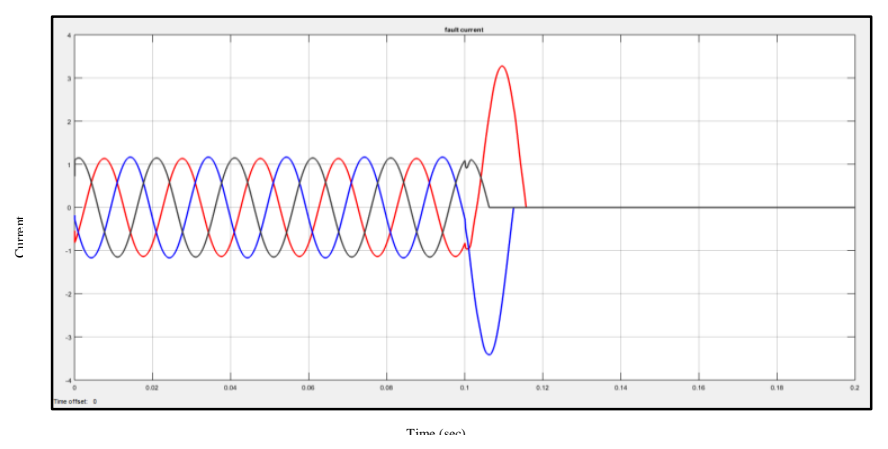

Figure 9: Current signal of double line to ground fault (A-B-G)

\subsection{LLL-G Fault}

Triple line to ground fault happens once three phases are shorted to ground. Figure (10) represented the triple line to ground fault, when the amplitude of the line current fault is upper than the ordinary input current as illustrated in figure (11). Thus the output waveforms shown an increasing in the current value at 3-phase to ground occurred.

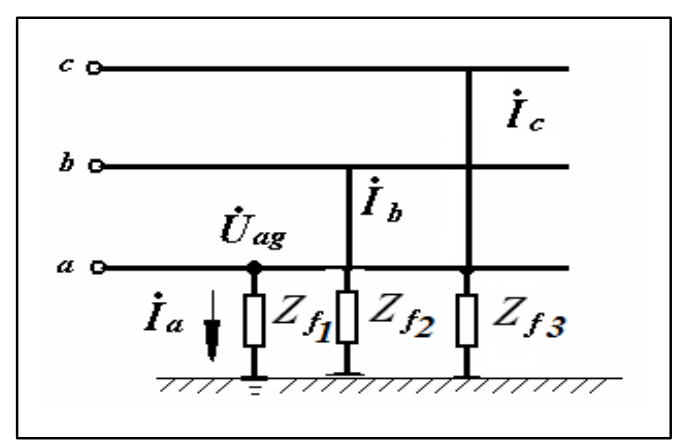

Figure 10: Triple line to ground fault 


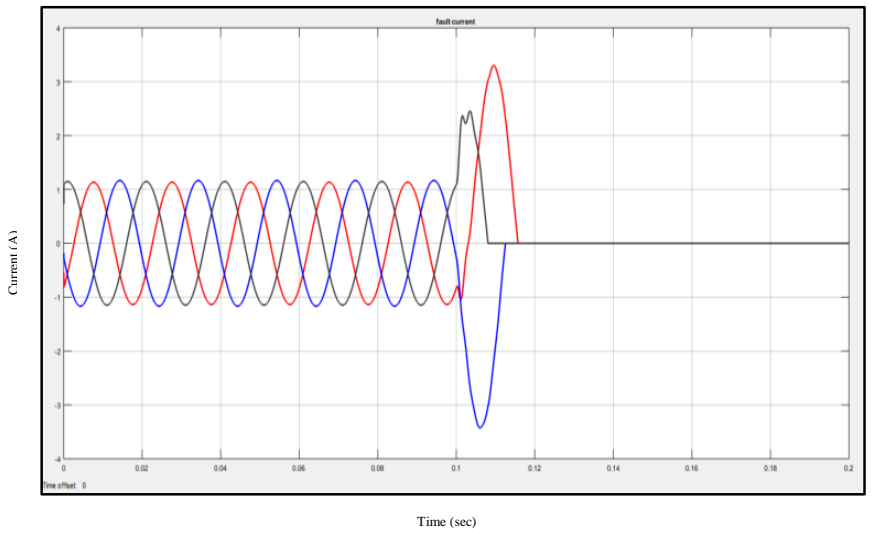

Figure 11: Current signal of three phase to ground fault (A-B-C-G)

\subsection{Line to Line Fault (A-B)}

Figure (12) represents the current output waveforms when two phases are short together without ground and detecting the fault point.

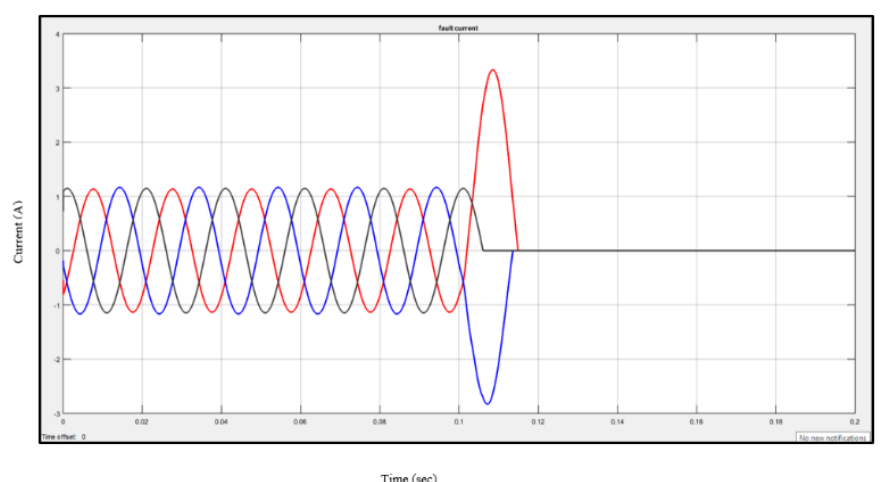

Figure 12: Current signal of double Line Fault (A-B)

\subsection{Triple-Line Fault (A-B-C)}

Figure (13) represents the current output waveforms when three phases are short together without ground and detecting the fault point.

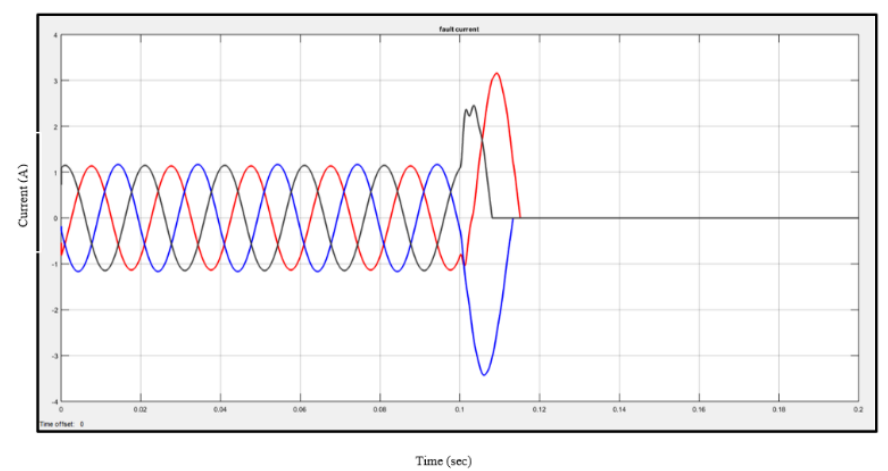

Figure 13: Current signal of three Phase Fault (A-B-C)

\section{CONCLUSIONS}

According to new algorithm of over current protection for faults occurring on transmission line a $(100 \mathrm{Km})$ transmission line (terco type) is simulated in MATLAB/SIMULINK with actual (real) parameters, waveforms of currents for each type of fault are obtained were appeared appositeness to factual cases and the assumptions on each case are also appeared appositeness to standard rater. The ordinary OCR is swimmingly modeled and simulated utilizing MATLAB/SIMULINK package. This declares that this package is ablest to be select any type of relay and modeling it. The time of simulation is accrediting on the intricacy of the model. Longer time may be needed for higher complexity of the model, in order to reduce the simulation time an appropriate simulation solver must be selected. The model selected in this article can readily be outreached to other kinds of curve such as ordinary over current type.

\section{REFERENCES}

[1] D. Birla, R. P. Maheshwari, and H. O. Gupta, "Timeovercurrent relay coordination: A review," International Journal of Emerging Electric Power Systems, vol. 2, no. 2, pp. 1-13, 2005.

[2] P. Maiji, G. Ghosh, "Designing Over-Current Relay Logic in MATLAB", International Journal of Scientific \& Engineering Research, vol. 8, no. 3, pp.1-10, 2017.

[3] A. Akhikpemelo, M. J. E. Evbogbai and M. S. Okundamiya, "Overcurrent relays coordination using MATLAB model", Journal of Engineering and Manufacturing Technology (JEMT), vol. 6, pp. 8-15, 2018.

[4] M. Param, and V. Makwana, "Modelling of overcurrent relay with inverse characteristics for radial feeder protection using graphical user interface," In 2017 International Conference on Intelligent Computing, Instrumentation and Control Technologies (ICICICT), pp. 74-79. IEEE, 2017.

[5] T. Cristina, F. E. Pérez, and F. L. Quilumba, "Wavelet Transform and Support Vector MachineBased Current-Only Directional Overcurrent Relay for Transmission Line Protection." In 2018 IEEE PES Transmission \& Distribution Conference and Exhibition-Latin America (T\&D-LA), pp. 1-5. IEEE, 2018.

[6] A. Yacine, A. Ayachi, A. N. Ayachi, H. Bentarzi, and F. Hamoudi, "Implementation of a Numerical Over-current Relay Using LabVIEW and Acquisition Card." In 2018 International Conference on Electrical Sciences and Technologies in Maghreb (CISTEM), pp. 1-5. IEEE, 2018.

[7] L. Chen, L. Xiangning, L. Zhengtian, W. Fanrong, J. Neng, L. Ran, and L. Chang, "Remedial pilot main protection scheme for transmission line independent 
of data synchronism." IEEE Transactions on Smart Grid, vol. 10, no. 1, pp. 681-690, 2017.

[8] J. Kunal, and A. S. Rao. "Over current protection of transmission line using GSM and Arduino." internatonal Journal of Engg. Trends \& Technology, vol. 50, no. 1, pp: 1-9, 2017.

[9] L. Staszewski, and R. Waldemar, "DLR-supported overcurrent line protection for blackout prevention." Electric Power Systems Research, vol. 155, pp. 104$110,2018$.

[10] N. Rezaei, M. Nasir Uddin, I. Khairul Amin, M. Lutfi Othman, and M. Marsadek, "Genetic Algorithm-Based Optimization of Overcurrent Relay Coordination for Improved Protection of DFIG Operated Wind Farms." IEEE Transactions on Industry Applications, vol.55, no. 6, pp. 5727-5736, 2019.

[11] F. B. Bottura, W. Bernardes, M. Oleskovicz, and E. N. Asada. "Setting directional overcurrent protection parameters using hybrid GA optimizer." Electric Power Systems Research, vol.143, pp. 400-408, 2017.

[12] M. Kheshti, T. Browh Serge, and K, Xiaoning. "The optimal coordination of over-current relay protection in radial network based on Particle Swarm Optimization." In 2016 IEEE PES Asia-Pacific Power and Energy Engineering Conference (APPEEC), pp. 604-608. IEEE, 2016.

[13] M. Nojavan, H. Seyedi, and M. Mehdinejad. "A novel scheme for current-only directional overcurrent relay." International Journal of Electrical Power \& Energy Systems, vol. 82, pp. 252-263, 2016.

[14] S. Manohar, V. Telukunta, and S. G. Srivani, "Enhanced real time coordination of distance and user defined over current relays." International Journal of Electrical Power \& Energy Systems, vol. 98, pp. 430-441, 2018.

[15] K. Jia, G. Chenjie, X. Zhenwen, L. Lun, and L. Yaoqi, "Fault characteristics analysis and line protection design within a large-scale photovoltaic power plant." IEEE Transactions on Smart Grid, vol. 9, no. 5, pp. 4099-4108, 2017.

[16] N. Rezaei, M. Nasir Uddin, I. Khairul Amin, M. Lutfi Othman, and M. Marayati, "Genetic algorithm based optimization of overcurrent relay coordination for improved protection of DFIG operated wind farms." In 2018 IEEE Industry Applications Society Annual Meeting (IAS), pp. 1-8. IEEE, 2018.

[17] B. A. Khan, M. A. Hafiz, H. Shahzaib, M. A, Rao, and U. Bashir. "Implementation of Micro Controller
Based Electromechanical Over Current Relay for Radial Feeder Protection." In 2019 International Conference on Engineering and Emerging Technologies (ICEET), pp. 1-6. IEEE, 2019.

[18] M. Rikta, S. Dolui, D. Agasti, and S. Biswas. "Micro-controller based over current relay using Hall Effect current sensor." In 2018 Emerging Trends in Electronic Devices and Computational Techniques (EDCT), pp. 1-4. IEEE, 2018.

[19] C. A. Castillo, and E. Fernandez. "Mitigation of DOCR miscoordination through distance relays and non-standard overcurrent curves." Electric Power Systems Research, vol. 163, pp. 242-251, 2018.

[20] S. Meng Yen, A. Conde, C. Angeles-Camacho, E. Fernandez, and Z. M. Leonowicz. "Mitigating the impact of distributed generation and fault current limiter on directional overcurrent relay coordination by adaptive protection scheme." In 2019 IEEE International Conference on Environment and Electrical Engineering and 2019 IEEE Industrial and Commercial Power Systems Europe (EEEIC/I\&CPS Europe), pp. 1-6. IEEE, 2019.

[21] P. Ray, P. M. Debani, and R. A. Sabha. "An Intelligent Approach for Protection Coordination of Overcurrent Relay in Smartgrid." In 2019 IEEE 1st International Conference on Energy, Systems and Information Processing (ICESIP), pp. 1-6. IEEE, 2019.

[22] A. Yazdaninejadi, S. Golshannavaz, D. Nazarpour, S. Teimourzadeh, and F. Aminifar. "Dual-setting directional overcurrent relays for protecting automated distribution networks." IEEE Transactions on Industrial Informatics, vol. 15, no. 2, pp. 730-740, 2018.

[23] A. Darabi, M. Bagheri, and G. B. Gharehpetian. "Highly sensitive microgrid protection using overcurrent relays with a novel relay characteristic." IET Renewable Power Generation, vol. 14, no. 7, pp. 1201-1209, 2020.

[24] D. Tzelepis, E. Tsotsopoulou, V. Nikolaidis, A. Dyśko, V. Papaspiliotopoulos, Q. Hong, and C. Booth, "Impact of synchronous condensers on transmission line protection in scenarios with high penetration of renewable energy sources." In IET 15th International Conference on Developments in Power System Protection. 2020.

[25] B. K. Sugumar, and S. Balaraman. "Implementation of Differential Algorithm for Busbar Protection." International Research Journal of Multidisciplinary Technovation, vol. 1, no. 2, pp. 150-157, 2019. 


\section{BIOGRAPHIES OF AUTHORS}
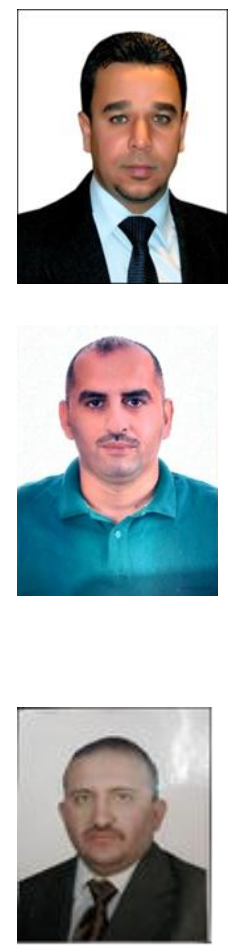

Mohammed Ahmed Ibrahim obtained his B.Sc. (2005) and M.Sc. (2011) in Electrical Power Engineering Technology from Northern Technical University (NTU). Currently, he is working as a lecturer in the Electrical Engineering, specializing in Electrical Power, at Northern Technical University (NTU)/Engineering Technical College, Mosul-Iraq.

Waseem Khalid Ibrahim obtained his B.Sc. (2004) in Electrical Power Engineering Technology from Northern Technical University (NTU) and M.Sc. (2016) in Electrical and Elecctronic Engineering degree from Bahçeşehir University (BAU), Istanbul-Turkey. Currently, he is working as a lecturer in the Electrical Engineering, specializing in Electrical Power Protection, at Northern Technical University (NTU)/Engineering Technical College, Mosul-Iraq.

Dr Ali Nathim Hamoodi obtained his M.Sc. (2000), and Ph.D. (2011) in electrical engineering, from the University of Aleppo, Syria. Currently, he is working as a lecturer in the Electrical Engineering, specializing in High Voltage, at Northern Technical University/Engineering Technical College (N.T.U), Mosul-Iraq. 